\title{
Empirical evidence of frequency of change and job burnout
}

\author{
R. Mat Zin ${ }^{\text {a* }}$ and A. Nehari Talet ${ }^{\mathrm{b}}$ \\ a'Department of Management \& Marketing, College of Industrial Management, \\ King Fahd University of Petroleum \& Minerals, P O Box 5074, 31261 Dhahran, Saudi Arabia \\ ${ }^{b}$ Department of Accounting \& MIS, College of Industrial Management, \\ King Fahd University of Petroleum \& Minerals, P O Box 5074, 31261 Dhahran, Saudi Arabia \\ *To whom all correspondence should be addressed \\ matali@kfupm.edu.sa
}

\begin{abstract}
This study focused on two main constructs; frequency of change (FoC) and the job burnout in the workplace. It employed a quantitative design to examine the relationship between employees' perceived "frequency of change" (FoC) occurring in their organizations and job burnout subscales - exhaustion, cynicism and professional efficacy. The respondents were low and middle level staff; managers and senior managers in selected manufacturing, information technology (IT) service organizations. Significant differences were found in levels of exhaustion between Financial Services employees and employees of other organization types. Finally, the difference was shown to exist in levels of cynicism between senior managers and employees when perceived FoC is high.
\end{abstract}

\section{Introduction}

Organizational change (OC) processes occur more frequently than not within modern organizations (Hila \& Tzafrir, 2011). Undeniably, organizational change constitutes a major area in the field of management and organization studies (Conner, 1993; Van de Ven \& Poole, 2005). Several academic journals devoted to the subject and an important number of articles and books published each year stand as a proof of its significance in the field Pettigrew (2011). Moreover, the focus on the subject is not exclusive to the academic sphere. Often, large-scale organizational changes make newspaper headlines and slight adaptations in our work adaptations populate our everyday talk. Therefore, whether it is the arrival of a new boss, a downsizing initiative or the introduction of a new work procedure, organizational change is an integral part of our experience of organizations. Thus, it is one of the main concerns of academics, practitioners and those who work day after day to sustain workplaces.

\section{Problem statement}

The most simplistic definition of change is "to make different in some particular" (Retrieved August 23, 2013 from http://wwwindiana.eduI-hange/defofchange.html). Often, however, the simplest definitions yield the most complex constructs. One of the most interesting aspects about individuals' reactions to change is that the same event can be perceived as a negative change by one person and a positive change by another (Conner, 1993). From this perspective, the actual amount of change occurring in an individual's workplace is irrelevant; it is the individual's perception of change that is important.
Demonstrating the relationship between too much change in the workplace and employee burnout will help leaders understand the impact change can have on the organization's employees and the organization as a whole.

\section{Study purpose}

Change has become a constant phenomenon, which must be attended to and managed properly if an organization is to survive (Gallego-Tolledo, 2015). The more that can be understood about how change impacts employee stress levels, the more that can be done to minimize its negative effects. The purpose of this study was to understand the relationship between employees' perceptions of change (FoC), occurring in their organization and their level of burnout. How these variables interact with an employee's position level within the organization and the organization type is also the interest of the study.

\section{Literature review}

\section{Frequency of change (FoC)}

The evolution of organizational change (OC) theory and practice dates back to Frederick Taylor's work in the late 1800s and early 1900s (Burke \& Noumair, 2015). During this era major changes in technological, socioeconomic, and cultural environmental conditions occurred. The economy, then driven by manual labor, became dominated by industry and the production of machinery (Malone, 2007)). Taylor's thinking and his work with organizations were heavily influenced by this industrial revolution. He viewed organizations as machines, studied them in scientific terms (Burke \& Noumair, 2015), and believed deeply that taking a scientific approach to organizational change would result in 
the best opportunity for change. Following Taylor, nine evolutions of organizational change were the forerunners of contemporary study and practice of organizational change (OC). The Hawthorne studies beginning in 1924 and going through 1933 were experiments to examine worker productivity and morale. These studies are significant to the understanding of organizational change because they demonstrated the significance of the human dimension of organization change (Burke \& Noumair, 2015).

An organizational change refers to any alteration in activities or task (Zabid et al., 2004). Kanter et al. (1992) defined OC as the process of analyzing the past to elicit the present actions required for the future. Burke (2011) believed that OC showed a diversity of the organization in its environment, and the interaction of the technical and human activities that had interrelated dimensions in the organization.

Organizational change can produce a number of positive and negative emotional responses that range from excitement and elation, through contentment to unease, fear, anger and disgust (Smollan, 2014) and which oscillate over time as events unfold. Emotions occur when outcomes are considered important and the processes that deliver them are evaluated. While change at the personal level can be analyzed in terms of its cognitive, affective and behavioral dimensions (Oreg et $a l ., 2011)$, it is the affective elements, which have been understudied in the literature (Smollan, 2014). This is surprising because emotional reactions to organizational change can be a major source of support or resistance (Szabla, 2007).

Organizational change can range from incremental changes (low Frequency of Change) within an operating model to radical modifications (high Frequency of Change) of operating methods, systems and applications (Safar, Defields, Fulop, Dowd, \& Zavod, 2006). Other types of organizational changes can include modifications to communication methods, compliance procedures, office procedures, and computer systems (Safar, et. al., 2006). Research has shown that too much change in too short a time (high Frequency of Change) can result in negative physical and psychological consequences for individuals.

It should be noted that Burke believed that transformational changes were uncommon, as he pointed out in his book Organization Change: Theory and Practice. Burke (2014) posited that in the business world, evolutionary change (low Frequency of Change) was more common than revolutionary change. The author explained that transformational or revolutionary change had a disruptive effect on the organization's overall performance, management, and employees' behaviors, requiring major change initiatives in the organization's mission, vision, strategy, leadership, and culture. Burke (2014) also stated that most organizational change, which was implemented on gradual scale, were positively perceived by employees.

\section{Job burnout}

Job burnout emerged as an important concept in the 1970s, and it captured something very critical about people's experience with work (Schaufeli, Leiter, \& Maslach, 2008). It continues to do so today, some 45 years since its introduction to psychological literature and to cultural discourse. Both then and now, job burnout has been a concept that seems to ring true to a common experience among people. It has inspired researchers to study it and try to better understand what it is and why it happens. It has inspired practitioners to figure out ways to cope with it, prevent it, or combat it. Thus, from the beginning, job burnout has enjoyed a joint recognition from both researchers and practitioners as a social problem worthy of attention and amelioration. As this recognition has spread too many other countries, beyond its American origins, it has become a phenomenon of notable global significance (Maslach \& Leiter, 2008).

Job burnout is a prominent problem that is plaguing organizations today (Bakker, et al., 2003; Fernet et al., 2010; Yavas et al., 2013). Maslach and colleagues (2001) described job burnout as a syndrome consisting of three components: exhaustion, cynicism, and professional efficacy, all of which could create negative effects for the individual and organization. This job burnout model emphasized all issues affecting individual workers, including the nature of work itself (Maslach et al., 1996). It is important to distinguish between the three jobs burnout components, since different studies (Bakker et al., 2003; Schaufeli \& Enzmann, \& Girault, 1998) have shown that each one has different causes and consequences.

Exhaustion reflects the strain of burnout (Maslach \& Leiter, 2008), and refers to being overextended and emotionally detached and depleted. This can manifest itself towards other employees, clients, or even family members, and has been associated with physical weakness.

Cynicism is the second component, and connotes depersonalization and a sense of detachment from the job, or aspects of it (Maslach \& Leiter, 2008); it also represents the interpersonal dimension of burnout, which is correlated with how workers approach colleagues in unconstructive ways (Maslach, 2001). Unconstructive behavior symbolizes cynicism includes distancing oneself from work and developing negative attitudes towards it (Bakker, Demerouti, Bour \& Schaufeli, 2003).

The third component of burnout is known as professional efficacy, which is synonymous with reduced accomplishment (Maslach, 2003). This also represents the self-evaluation facet of burnout, referring to feelings of incompetence and poor achievement; it is largely independent of emotional exhaustion and depersonalization, and based on interactions with recipients and occupational accomplishments. The other two are more likely to be determined by job setting factors (Bakker et al., 2003). 
Several scales exist that all purport to measure job burnout (Alarcon \& Edwards, 2011), however, the most commonly utilized scale is the Maslach Burnout Inventory (MBI) (Maslach et al., 2001). This scale consists of three subscales: exhaustion, cynicism, and professional efficacy. Having been proven both reliable and valid through extensive testing, the MBI scale was chosen for this study.

\section{Correlates between organizational change (frequency of change) and job burnout}

Scholars suggest that there is significant relationship between organizational changes in general with job burnout (Schaufeli and Bakker, 2004). The high demands and pressures from the organizational change efforts lead to job such emotional depression (Hakanen, Schaufeli \& Ahola, 2008, as well as higher rates of organizational cynicism, reduced well-being, and poor performance (Chiu \& Tsai, 2006). It has negative consequences for both persons afflicted by it, as well as their organizations where they work (Kahn et al., 2006)..

Individuals with ongoing challenges during the organizational change programs implemented in their respective organizations experiences emotional fatigue, whereas those who are mentally exhausted may distance themselves as a coping mechanism to preserve their stamina on the job. Chen's findings (2011) suggested that hospitality managers who experienced high frequency of change (FoC) reported lower degrees of job burnout on professional efficacy scales.

In another study conducted by Law (2010) who surveyed 163 business students to assess the level of job burnout, found that during undue duress (such as end of the term finals) they scored high on the exhaustion scale. Business students who undergo too many changes (high FoC) in the curriculum throughout their study programs had a mean score of 3.79 , which is quite high compared to exhaustion scores as measured in other professions such as social workers 2.37 and mental health workers 1.88 during their organizational transformation process. Law (2010) also found that exhaustion for business students dropped off after the term was over and there was a break in demands. Therefore, it is helpful to know that the exhaustion component of job burnout can be reduced when work stress subsides due to reduced frequency of change activities.

In another study (Pappenfus, 2013) investigated whether there was a relationship between frequency of change in organizations and job burnout among HR professionals. The sample included $147 \mathrm{HR}$ professionals who completed the Maslach Burnout Inventory (MBI), which measured burnout and the Frequency of Change Scale (FoC) which measured change momentum. The results indicated that the frequency of change in an organization does not have a significant effect on each job burnout subscales namely, exhaustion, cynicism and professional efficacy among the HR professionals. In addition, no relationships were found between gender and job position levels of the respondents.
Research by Simha, Elloy and Huang (2014) has shown that too much change (high FoC) in too short a time can result in negative physical and negative physical and psychological consequences for individuals. One such result is job burnout, which is comprised of three components: Emotional Exhaustion, Depersonalization and Reduced Personal Accomplishment.

Using four different surveys (the Workplace Incivility Scale, the Measure of Cynicism about Organizational Change, the Maslach Burnout Inventory-General Survey, and the Frequency of Change Scale), Gallego-Toledo (2015) studied the relationship between the effects of perceived frequency of change on the wellbeing of telecommunications professionals in the United States. The three wellbeing criterion variables (job burnout level, organizational cynicism, and incivility level), and the demographics of the respondents (age group, gender, hierarchical position, and years in the telecommunications industry) were adopted in the research model. The researcher found a significant relationship between predictor variable, perceived frequency of change (FoC), and the criterion variables: job burnout level; incivility level, and organizational cynicism. The multiple linear regression study found no moderating effect between the demographic variables, FoC and the incivility level but hierarchical level was found to play a moderator role in the relationships between FoC and burnout level, and between FoC and organizational cynicism.

Based on the above literature review, the following hypotheses are formulated as below and the Research Model was developed as depicted in Figure 1: Hypothesis 1. There is not a significant correlation
between the perceived FoC in the workplace and
levels of burnout.

Hypothesis 1.1 There is not a significant correlation between the perceived FoC in the workplace and exhaustion.

Hypothesis 1.2. There is not a significant correlation between the perceived FoC in the workplace and cynicism.

Hypothesis 1.3. There is not a significant correlation between the perceived FoC in the workplace and professional efficacy.

Hypothesis 2. There is not a significant interaction between perceived $F_{O} C$ and position level within the organization when explaining the levels of burnout in the workplace.

Hypothesis 3. There is not a significant interaction between perceived $\mathrm{FoC}$ and type of organization when explaining the levels of burnout in the workplace. 


\section{Research methodology}

\section{Respondents}

Five organizations which participated in this study were as follows: (a) The Saudi Telecom Company: Jeddah Office ;(b) The Saudi British Bank; Jeddah Branch; (c) The Al-Zammil Construction Company; Jeddah Office; (d) The King Abdul Aziz City University; and (e) The Saudi Airlines, Headquarters Office.

Two hundred full-time employees who are working in these organizations at their respective offices in Riyadh and Jeddah were randomly selected as the study respondents using the Staff Directory Listings. The respondents were from three levels of workers categories (employees, middle managers, and senior manages) who working in eight (8) different business areas (1) Sales \& Services; (2) Information Technology; (3) Human Resources; (4) Product Development; (5) Marketing; (6) Operations; (7) Finance; and (8) Legal.

\section{Instruments}

Two instruments were used as part of this study: the FoCS, which was designed for this study, and the MBI-GS (Maslach et al., 1996). Following is a more detailed background on the instruments used: (a) Frequency of Change Scale. The FoCS was designed to measure the amount of change perceived to have occurred in the participant's organization over the preceding year. Participants were asked to indicate their perceptions of change frequency related to organizational structure, work processes, performance measures, job descriptions, job titles, and other variables. Items were scored on a 5-point Likert scale with values of 1 (never), 2 (once or twice), 3 (not sure/not applicable), 4 (often), and 5 (very often); (b) Maslach Burnout Inventory--General Survey. The MBI-GS (Maslach et al., 1996) is a 16-item questionnaire designed to measure burnout in occupational groups other than human service providers. The instrument measures respondents' feelings about their work, on a continuum from engagement to burnout. The MBI-GS measures burnout along three subscales: Exhaustion, Cynicism, and Professional Efficacy. The MBI-GS was scored on a 7-point Likert scale ranging from 1 (never) to 7 (every day) (see Table 1). A high degree of burnout is indicated by high scores on the Exhaustion and Cynicism scales together with low scores on the Professional Efficacy scale. Test reliability coefficients were measured and the results are displayed in Table 2.

\section{Data analysis}

The data were verified; means and standard deviations were calculated for all variables, and then statistical analysis was performed to answer the hypotheses developed for the study. For Hypothesis 1, Pearson's correlation coefficients were calculated to determine the relationship between perceived frequency of change (as a continuous variable) and levels of burnout. Levels of burnout were reported both as a composite score and in terms of the three factors of the MBI-GS. For
Hypothesis 1-3, a factorial multivariate analysis of variance (MANOVA) was conducted simultaneously to evaluate the interactions between perceived FoC, position level, organization type, and the three burnout subscales. Three one-way analysis of variance (ANOVA) calculations were then performed to determine the interactions between each independent variable and each burnout subscale separately. Where results were significant, post hoc comparisons were conducted to investigate pairwise differences among factors.

\section{Research findings}

\section{Analysis of demographic factors}

Tables 3-8 displays the demographic factors of the respondents participating in this study.

\section{Inferential statistical analysis}

To test the Hypothesis 1 (Hypothesis 1.1; Hypothesis 1.2: Hypothesis 1.3) posed by this study, Pearson's product moment correlation coefficient was first calculated to evaluate the relationship between the mean composite FoC score and (a) each sub scale of the MBI-GS, and (b) the composite MBI-GS score. To analyse Hypothesis 2 and Hypothesis 3 a factorial MANOVA was performed to evaluate the effects of FOC and the interactions between perceived $\mathrm{FoC}$ and position level and organization type on the three burnout subscales. Follow-up ANOVAs then evaluated these same effects on each burnout subscale separately. Full MANOVA results are shown in Table 9.

Only two effects were significant in the overall MANOVA: a significant three- way interaction between perceived FoC, Organization Type, and Position Level, $(\mathrm{p}=0.000)$ and a marginal main effect of Organization Type $(\mathrm{p}=.050)$. Following are the results for each hypothesis individually.

\section{Hypothesis 1. There is not a significant correlation between the perceived $F_{0} C$ in the workplace and levels of burnout.}

Hypothesis 1.1 There is not a significant correlation between the perceived FoC in the workplace and exhaustion.

Hypothesis 1.2. There is not a significant correlation between the perceived FoC in the workplace and cynicism.

Hypothesis 1.3. There is not a significant correlation between the perceived $\mathrm{FoC}$ in the workplace and professional efficacy.

There is a significant correlation between the perceived FoC in the workplace and overall levels of burnout, which is predicted in Hypothesis 1. Thus, the null hypothesis for Hypothesis 1 is rejected. When correlating each MBI-GS subscale separately with perceived FoC, only the Exhaustion subscale (Hypothesis 1.1) was shown to exhibit a significant 
correlation. Both the Cynicism (Hypothesis 1.2) and Professional Efficacy (Hypothesis 1.3) subscales were not shown to have a significant correlation with perceived FoC. Table 10 presents the strength of these correlations.

Hypothesis 2. There is not a significant interaction between perceived FoC and position level within the organization when explaining the levels of burnout in the workplace.

Results of the MANOVA (Table 9) show that mean differences across FoC levels in the composite burnout score were not significantly different across position levels (Wilks' $\mathrm{A}=.838 ; \mathrm{p}=.127)$. Mean burnout scores for each combination of FoC and Position Level are shown in Table 11 below.

Follow-up ANOVA calculations (Table 14) show significant interactions between perceived FoC and Position Level on Cynicism. Despite this result, pairwise comparisons show no significant differences in Cynicism scores across all threeposition levels.

Pair-wise comparisons do show a significant interaction between employees and senior managers (Mean Difference $[\mathrm{MD}]=5.922, \mathrm{p}=.07$ ), with a $95 \%$ confidence interval of .456 to 12.30 when perceived FoC is high. However, because the interaction of perceived FoC and Position Level was not significant in explaining overall levels of burnout, the null hypothesis for Hypothesis 2 is accepted.

Hypothesis 3. There is not a significant interaction between perceived FoC and type of organization when explaining the levels of burnout in the workplace.

MANOVA results (Table 9) show a significant main effect of organization type when explaining levels of burnout (Wilks' $\mathrm{A}=.844, \mathrm{p}=.056$ ). Follow-up ANOVAs (Table 13) show significant differences between organization types when explaining levels of Exhaustion, but not when explaining levels of Cynicism or Professional Efficacy.

Mean composite burnout scores by perceived FoC levels and Organization Type are shown in Table 14. Pair-wise comparisons were then performed to analyse the differences in burnout composite scores based on Organization Type. Differences between Financial Services and each of the other organization types (Information Technology, Operations, and Sales and Services) were significant (Table 15), for the Exhaustion subscale, and the overall burnout score. However, no other pair-wise differences were significant. Although there were significant main effects for organization type, there were no significant effects of the interaction between organization type and perceived FoC in explaining burnout. The null hypothesis for Hypothesis 3 was accepted.

\section{Discussions and recommendations}

The findings demonstrate that significant relationships exist between perceived FoC and burnout, and between perceived FoC and exhaustion. To some extent, these two findings supported the conclusion derived from Simha, et al.; 2014). Further, there is a significant difference in levels of exhaustion between employees of Financial Services organizations and other organization types. When perceived FoC is high, Senior Managers experience higher levels of cynicism than employees. However, there is not a significant difference in perceived FoC based on position level when explaining levels of burnout.

Other recent studies found that predictors of burnout include increases in job demands and decreases in job resources (Xanthopoulou, Bakker, Dollard \& Demerouti, 2007; Schaufeli, Bakker, \& Rhenen, 2009). This finding directly correlates to this study in that questions included in the FoC are directly related to increases in job demands. Specifically, questions 3,5 , and 6 , which ask, "how often has your work processes changed, "how often have your work hours been changed," and "how often has your job description changed," directly speak to increases in job demands.

The relationship between perceived FoC and exhaustion is consistent with the results of a study that used the MBI-GS to assess the relationship between vicarious trauma work and burnout among registered psychiatric nurses (Robinson et al., 2003). Robinson et al. found no significant relationship between vicarious trauma and burnout. High scores on the Emotional Exhaustion subscale were related to frequent interruptions while working, too much responsibility, and many hours of work per week, all of which can be categorized as increased job demands.

This study found a significant difference in levels of exhaustion between employees of Financial Services organizations and employees of other organization types. It means that although Financial Services' employees do not experience higher levels of burnout, they do experience higher levels of exhaustion than employees of other organization types.

An unexpected finding of this study was that when perceived FoC is high, Senior Managers display higher levels of cynicism than employees. This finding indicates that Senior Managers who perceive a large amount 'of change to be taking place in their organizations are more cynical than Employees who perceive a large amount of change taking place.

\section{Recommendations}

This study showed that a relationship does exist between employees' perceived FoC and their level of burnout. Further, employees of Financial Services organizations are experiencing higher levels of exhaustion than their counterparts at other types of organizations. This study has added a valuable body of knowledge to the field of OD related to the impact that too much change can have on employee job performance, which can, in turn, have a negative impact on the health of the organization. 
The original intention was that this study be conducted within one or more organizations to determine trends related to the FoC as perceived by an organization's employees and the level of employee burnout. Although the researcher was unable to conduct the study as intended, it is believed that doing so would yield different results, particularly if the study focused on Financial Services organizations compared against other organization types. Such a study would also measure differences in FoC and burnout based on business areas within each company in addition to organization type. Although business area was a demographic collected for this study, it was determined that organization type was a more relevant variable given the study population.

Despite the study not being conducted as originally intended, the results of this study as conducted have revealed several additional areas for further research. One such area would include a study on the relationship between perceived FoC, burnout, and organizational factors such as profitability and customer satisfaction, in order to examine the relationship between too much change and organizational health.

As previously stated, the scope of this study did not allow for determining cause and effect between perceptions of organizational change and burnout. A more thorough study would consist of a longitudinal study, measuring perceptions of organizational change, level of burnout, and job performance, taking measurements of these constructs before, during, and after a large-scale change. This study would be required to be conducted at individual organizations in order to determine whether these relationships have a negative impact on organizational performance, which would be a fourth construct to be measured. If the employee constructs are shown to have an impact on organizational performance, this knowledge would a valuable addition to the body of knowledge surrounding organizational health.

Finally, this study should be replicated during a time when the Saudi Arabia is not experiencing an economic recession with high inflation and unemployment rate, in order to determine if the current economic climate is a factor in the study's findings. Replication of the study may reveal whether or not the economic climate and its impact on Financial Services organizations was a factor in the difference in employee exhaustion levels between Financial Services and other types of organizations. Further, replication of this study may also reveal whether the economic climate results in an impact to cynicism levels between Senior Managers and Employees when perceived FoC is high.

\section{Conclusion}

This study began with a desire on the part of the researcher to study the impact of too much change in too short a time on organizational health. The theory underlying this desire was that the psychological health and stability of an organization's workforce was an important factor in maintaining a healthy and profitable organization. However, due to the lack of a concise definition of organizational health and a tool with which to measure it, the construct of employee burnout was selected as one indicator of the state of an organization's health.

Of the three Hypotheses addressed by this study, the null hypothesis was rejected for three of them. A relationship was shown to exist between perceived FoC and overall levels of burnout, as well as between perceived FoC and Exhaustion. Additionally, significant differences were found in levels of exhaustion between Financial Services employees and employees of other organization types. This may be directly related to the current economic crisis and cost-cutting measures taken by many Financial Services organizations, particularly in the form of downsizing. Job insecurity among surviving employees may play a role in level of burnout, as well as increased job demands, which is a predictor of burnout (Schaufeli, Bakker, \& Rhepen, 2009). Finally, a difference was shown to exist in levels of cynicism between Senior Managers and Employees when perceived FoC is high.

\section{References}

Alalrcon, G. \& Edwards J. 2011. 'The relationship of engagement, job satisfaction and turnover intentions', Stress and Health. 27(1): 294-298.

Bakker, A., Demerouti, E., Boer, E. \& Schaufelia, W. 2003. 'Job demands and job resources as predictors of absence duration and frequency', Journal of Vocational Behavior, 62(3): 342-256.

Burke, W.W. \& Noumair, D.A. 2015.Organization development: A process of learning and changing. 3rd Edition. Upper Saddle River, NJ: Pearson Education

Burke, W.W. 2014. Organization change: Theory and practice. 4th ed. Thousand: CA, Sage Publication.

Burke, W.W. 2011. 'A perspective on the field of organization development and change: The Zeigarnik effect', Journal of Applied Behavioral Science, 47(1): 143-167.

Chen, I.S. 2011. 'Choosing the right channels of communication and moderating stress levels during organizational change', International Journal of Management and Innovation, 3(1): 43-44.

Chiu, S.F. \& Tsai, M.C. 2006. 'Relationships among burnout, job involvement, and organizational citizenship behavior', The Journal of Psychology, 140(6): 517.

Conner, D.R. 1992. Managing at the speed of change: How resilient managers succeed and prosper where others fail. New York: Villard Books, Random House, Inc.

Gallego-Toledo, J.M. 2015.The relationship between perceived frequency of change and the wellbeing of telecom professionals. Unpublished PhD dissertation submitted to the University of the Rockies, 193 pages.

Hakanena, J., Schaufeli, W. \& Aholaaa, K 2008. 'The job demandsresources model: A three-year cross-lagged study of burnout, depression, commitment, and work engagement', Work \& Stress. 20(3): 224-241.

Indiana University Press (2013). Definition of change. [online]. URL . http://wwwindiana.eduI-hange/defofchange.html. 
Law, D. 2010. 'A measure of burnout for business students', The Journal of Education for Business. 85(4): 131-144.

Kanter, R.M., Stein, B.A. and Jick, T.D. 1992. The challenge of organizational change. New York: The Free Press.

Malone, S.A. 2007. Creating organizational capacity for continuous and adaptive change. Unpublished PhD dissertation submitted to Benedictine University. ProQuest Publishing, 215 pages.

Oreg, S., Vakola, M. \& Armenakis, A. 2011. 'Change recipients' reactions to organizational change: A 60 -year review of quantitative studies', Journal of Applied Behavioral Science, 47(3): 461-524

Pappenfus, B. 2013. How frequency of change within organizations affects burnout of human resource professionals. Unpublished PhD dissertation submitted to the Cappella University, ProQuest Publishing, 131 pages.

Pettigrew, T.F \& Tropp. L.R. 2011. When groups meet: The dynamics of inter-group contact. Philadelphia, PA: Psychology Press.

Robinson, 3.R., Clements, K. \& Land, C. 2003. 'Workplace stress among psychiatric nurses', Journal of Psychosocial Nursing and Mental Health Services, 41(4): 32.

Safar, J.A., Defields, C, Fulop, A., Dowd, M. \& Zavod, M. 2006. 'Meeting business goals and managing office bandwidth: A predictive model for organizational change', Journal of Change Management, 6(1): 87.

Simha, A, David, E. \& Huang, H.C. 2014. 'The moderated relationship between job burnout and organizational cynicism. Management Decision, 84(1). 504-482.

Schaufeli, W.B., Bakker, A.B. \& Van R.W. 2009. 'How changes in job demands and resources predict burnout, work engagement, and sickness absenteeism', Journal of Organizational Behavior, 30(7): 893.

Schaufeli, W.B., Leiter, M. \& Maslach, C. 2008. 'Burnout: 35 years of research and practice', Career Development Journal, 14(4): 204220.

Schaufeli, W.B. \& Bakker, A.B. 2004. 'Job demands, job resources, and their relationship with burnout and engagement: A multi-sample study', Journal of Organizational Behavior, 25(2): 293-315.

Schaufeli, W.B. \& Enzmann, D. 1998. The burnout companion to study and practice: A critical analysis. London: CRC Press.

Smollan, K.R. 2014. 'Control and the emotional rollercoaster of organizational change', International Journal of Organizational Analysis, 22(3) : 419-399.

Szabla, D.V. 2007. 'A multidimensional view of resistance to organizational change: Exploring cognitive, emotional, and intentional responses to planned change across perceived change leadership strategies', Human Resource Development Quarterly, 121(3), 525-558.

Van de Ven \& Poole, M. 2005. 'Alternative approaches for studying organizational change', Organization Studies, 26 (4): 1377-1404.

Xanthopoulou, D., Bakker, A.B., Dollard, M.F. \& Denierouti, E. 2007. 'When do job demands particularly predict burnout? The moderating role of job resources', Journal of Managerial Psychology, 22(8): 766.

Zabid, A.R., Murali, S. \& Abdul Rahman, A. 2007. 'The influence of organizational culture on attitudes toward organizational change', Leadership \& Organization Development Journal, 25(1/2): 161179.

\section{Acknowledgement}

The authors would like to express our heartfelt gratitude to KFUPM for funding this research through SABIC Research Funds (Project No. SB101027). We also would like to thank all the respondents for their generosity in participating in this research. 